\title{
Fabrication of covalently-bonded polystyrene/SiO composites by Pickering emulsion polymerization
}

\author{
Dezhong Yin • Qiuyu Zhang • Hepeng Zhang • \\ Changjie Yin
}

Received: 15 July 2009 / Accepted: 28 October 2009 /Published online: 25 November 2009

(C) The Author(s) 2009. This article is published with open access at Springerlink.com

\begin{abstract}
Pickering emulsion polymerization has attracted considerable attention in material fabrication due to its unique surfactant-free character and versatile association of oil, water and particles for a large set of materials. In this study, $\mathrm{SiO}_{2}$ modified with Methacryloxypropyltrimethoxysilane (MPTMS) was employed to prepare Pickering emulsion, and subsequently covalently-bonded polystyrene/ $\mathrm{SiO}_{2}\left(\mathrm{PS} / \mathrm{SiO}_{2}\right)$ composites were synthesized by Oil-inwater Pickering emulsion polymerization. Optical micrograph, contact angle, thermogravimetric analysis (TGA), Fourier transform infrared spectra (FT-IR), scanning electron microscope (SEM) and dynamic laser scattering (DLS) were employed to characterize the modified $\mathrm{SiO}_{2}$, Pickering emulsion and prepared composites. It was found that prepared composites possess ragged surface morphology and $\mathrm{SiO}_{2}$ concentration has an important effect on the morphology of as-prepared composites. In addition, covalent bond between PS core and $\mathrm{SiO}_{2}$ shell was evidenced by FT-IR.
\end{abstract}

Keywords Pickering emulsion · Hybrid composites ·

Surfactant-free polymerization

\section{Introduction}

Emulsion polymerization possesses distinguished advantages such as facilitate controlling and high degree of polymerization. Surface-active agent, typically as surfactant

D. Yin $\cdot$ Q. Zhang $(\bowtie) \cdot$ H. Zhang $\cdot$ C. Yin

School of Science, Northwest Polytechnical University,

No.127, Youyi West Road,

Xi'an City, Shanxi Province, China

e-mail: qyzhang1803@gmail.com with low molar mass, is essential in emulsion to stabilize droplet from coalescence. However, it has been recognized that recycling the surfactant after polymerization is rather tedious and the surfactant has negative effect on the products and potential crisis to the environment.

Besides surfactants, colloidal particles can also be used to protect droplets from coalescence and stabilize Pickering emulsion, as summarized systematically by Robert Aveyard in 2003 [1]. Subsequently extensive interests and studies have been focused on it due to its surfactant-free character [2-6]. Using solid particles, conventional emulsifying agents can be reduced and hazardous surfactants may be replaced by less harmful materials. In some cases, organic emulsifying agents can even be completely avoided. This is the dominant reason that Pickering emulsion is of growing interesting in food engineering $[7,8]$ and pharmaceutical fields $[9,10]$.

Recently, arising interesting and efforts have been focused on fabrication of materials by Pickering emulsion. It have demonstrated theoretically and experimentally that Pickering emulsion polymerization is a feasible way for the preparation of organic (core)-inorganic (shell) hybrid composites. In Pickering emulsion, solid particles anchor irreversibly on the surface of droplet. After polymerization, solid particles form a spherical inorganic shell while polymerizable monomer droplet forms an organic core. The versatile association of monomer droplet, water and solid particles in Pickering emulsion allows a large set of composites to be prepared, e.g. polyaniline $(\mathrm{PANI}) / \mathrm{CeO}_{2}$ [11], $\mathrm{PANI} / \mathrm{SiO}_{2}$ [12], PANI/ $\mathrm{Cu} 2(\mathrm{OH}) 2 \mathrm{CO} 3$ [13], polystyrene(PS)/ZnO [14], poly(vinyl acetate)/ $/ \mathrm{SiO}_{2}$ [15]. However, no strong covalent bond exists between the inorganic shell and organic core of the obtained composites, because solid particles employed in the literatures are inert in chemical reaction, i.e., have no polymerizable groups on their surfaces. 
Herein, nano- $\mathrm{SiO}_{2}$ particles modified by methacryloxypropyltrimethoxysilane (MPTMS) were employed to prepare Pickering emulsion, followed by radical polymerization initiated by Azobisisobutyronitrile (AIBN) to fabricate $\mathrm{PS} / \mathrm{SiO}_{2}$ hybrid composites. By variety of MPTMS amount, wettability of $\mathrm{SiO}_{2}$ particles was tuned significantly. Furthermore, $\mathrm{SiO}_{2}$ particles were functionalized with reactive $\mathrm{C}=\mathrm{C}$ groups which can copolymerize with styrene during polymerization. As a result, the interaction between $\mathrm{SiO}_{2}$ shell and PS core was enhanced.

\section{Experimental}

\section{Materials}

Nano- $\mathrm{SiO}_{2}$ particles with an average diameter of $20 \mathrm{~nm}$ were provided by GuangzhouYixin New Material Co. (Guangzhou, China). MPTMS and AIBN were obtained from Beijing Chemical Reagent Co.LTD (Beijing, China). Styrene was supplied by Shanghai Shanpu Chemical Reagent Co. (Shanghai, China). $10 \% \mathrm{NaOH}$ solution was used to eliminate inhibitor in styrene, followed by rinse with distilled water to $\mathrm{pH}$ 5.0. Other reagents are analytical grade and used as received.

\section{Modification of $\mathrm{SiO}_{2}$ particles}

The modification of $\mathrm{SiO}_{2}$ was carried out in ethanol/water media based on the hydrolysis/condensation between Si$\mathrm{OH}$ of $\mathrm{SiO}_{2}$ surface and hydrolyzed MPTMS. In a typical procedure, $3 \mathrm{~g}$ of $\mathrm{SiO}_{2}$ particles was added to $100 \mathrm{~mL}$ of ethanol/ammonia $(1 \mathrm{M})$ mixture $(3 / 1, V / V)$ and dispersed using a Nankun 250-SW ultrasonic processor (Kunshan Experimental Instrument, China) for $15 \mathrm{~min}$. A definite amount of MPTMS was added into the suspension under vigorous magnetic agitation and reacted at room temperature under moderate agitation for $8 \mathrm{~h}$ or $24 \mathrm{~h}$. After reaction, the suspension was centrifuged at $6,000 \mathrm{rpm}$ and the collected $\mathrm{SiO}_{2}$ particles were washed by dispersion into ethanol and centrifugation for three times. Finally, the $\mathrm{SiO}_{2}$ particles were ultrasonically dispersed in distilled water.

Preparation of $\mathrm{PS} / \mathrm{SiO}_{2}$ composites by Pickering emulsion polymerization

$\mathrm{PS} / \mathrm{SiO}_{2}$ composites were synthesized by Pickering emulsion polymerization initiated by AIBN. A typical preparation procedure is detailed as follows: $1.0 \mathrm{wt} \%$ of AIBN was dissolved in styrene to form oil phase, and subsequently the oil phase was mixed with the $\mathrm{SiO}_{2}$ suspension described above. A stable Pickering emulsion was generated by means of an Ultrasonic processor (Kunshan,China) for $5 \mathrm{~min}$. The emulsion obtained was subsequently discharged into a reactor to conduct polymerization under mildly stirring $(30 \mathrm{rpm})$ at $55^{\circ} \mathrm{C}$ for $4 \mathrm{~h}$ and $65^{\circ} \mathrm{C}$ for another $4 \mathrm{~h}$. The obtained $\mathrm{PS} / \mathrm{SiO}_{2}$ composites were filtrated and washed with water and ethanol respectively, followed by dried in vacuum at $45^{\circ} \mathrm{C}$.

\section{Characterization}

The type of Pickering emulsion was inferred by observing what happened when a drop of emulsion was added into pure water or styrene. Styrene-in-water emulsions were dispersed in water and remained as drops in styrene, while water-in-styrene emulsions were dispersed in styrene and remained as drops in water [16]. The contact angle of particles was determined by a JY-82 contact angle goniometer (Chengde, China). Optical micrographs were obtained using a DMM-330C microscope (CAIKON, Shanghai) equipped with a high speed digital camera and a super scale-demarcation software. TGA analysis was carried out with a HTG-1/2 thermogravimetric analyzer (HenJiu, China). SEM images were collected by a Hitachi S-2700 electron microscopy (Hitachi, Japan). FTIR spectra were obtained using a BRUKER Tensor27 FTIR spectrometer (Bruker, Germany). The diameter of the composites were detected using a LS13321 Laser Diffraction Particle Size Analyzer (Berckman, USA).

\section{Results and discuss}

Distribution of $\mathrm{SiO}_{2}$ particles on Styrene/water interface

By variety of amount of MPTMS and modification time, $\mathrm{SiO}_{2}$ particles modified with different wettability were prepared, denoted as $\mathrm{Si}-10 \mathrm{a}$ (MPTMS employed equal to 10 $\mathrm{wt} \%$ of $\mathrm{SiO}_{2}$ amount and the modification lasted for $8 \mathrm{~h}$ ),

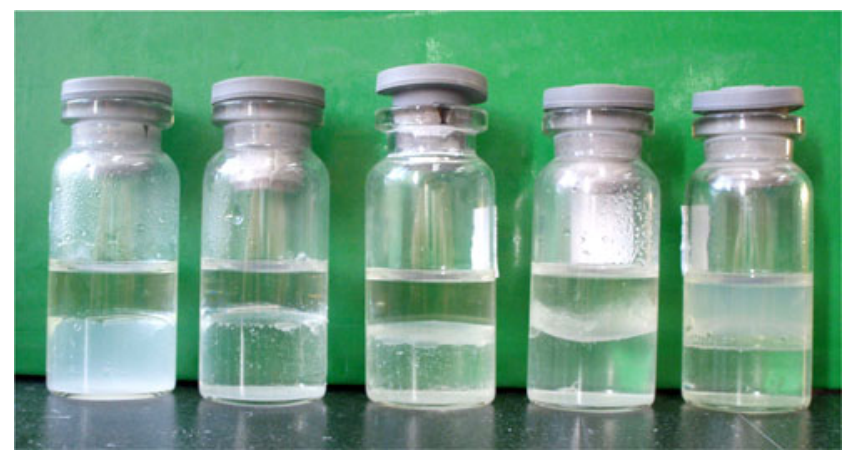

Fig. 1 Distribution in dual-phase system of $\mathrm{SiO}_{2}$ particles. The $\mathrm{SiO}_{2}$ used from left to right are original $\mathrm{SiO}_{2}, \mathrm{Si}-10 \mathrm{a}, \mathrm{Si}-10 \mathrm{~b}, \mathrm{Si}-15$ and Si30 respectively 


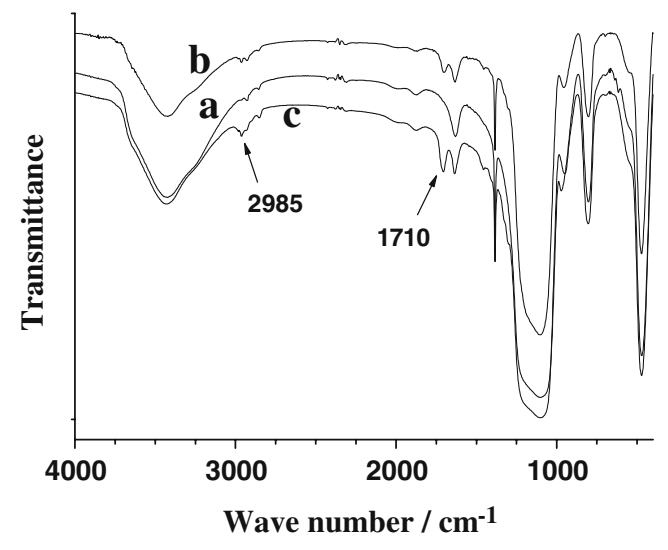

Fig. 2 FT-IR Spectra of original $\mathrm{SiO}_{2}(a), \mathrm{Si}-10 \mathrm{~b}(b)$ and $\mathrm{Si}-30(c)$

Si-10b (10\%, 24 h), Si-15 (15\%, 24 h) and Si-30 (30\%, $24 \mathrm{~h})$.

The adsorption of colloidal particles at oil/water interface is a crucial factor for preparing stable Pickering emulsions [3, 17]. In order to probe into the wettability of the particles, their behavior when they are suspended in a styrene/water dual-phase mixture was observed. Three drops of $\mathrm{SiO}_{2}$ suspension were dropped into styrene/water mixture, followed by violent shaking and settling undisturbed. Particles with different modified procedures present different behavior as shown in Fig. 1. Original silica particles disperse only in water due to hydrophilic $\mathrm{Si}-\mathrm{OH}$ groups on their surface, while $\mathrm{Si}-30$ particles disperse preferentially in styrene due to their hydrophobicity caused by modified MPTMS. Particles with middle degree of modification (Si-10a, Si-10b and $\mathrm{Si}-15)$ assemble spontaneously at the water-styrene interface.

The difference of distribution behavior is originated from the difference of MPTMS amount on the particle surface, as evidenced straightly by FTIR spectra in Fig. 2 and TGA in Fig. 3. In FTIR spectra, besides the characteristic bands of

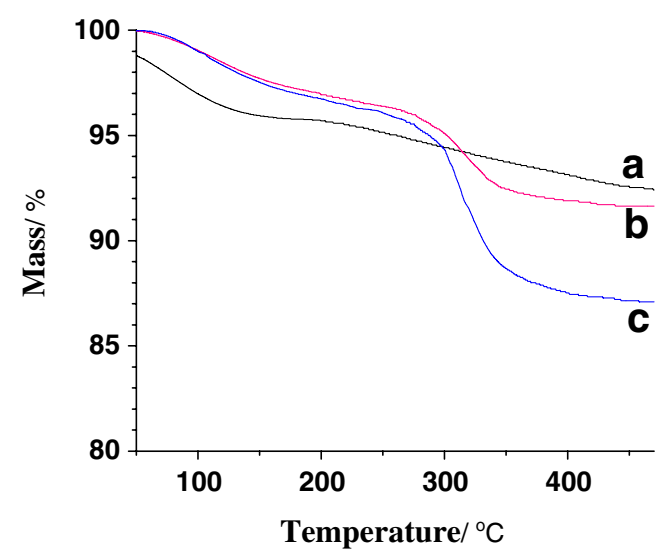

Fig. 3 TGA curves of (a) original $\mathrm{SiO}_{2},(b) \mathrm{Si}-10 \mathrm{~b},(c) \mathrm{Si}-30$
Table 1 Contact angle of modified $\mathrm{SiO}_{2}$ particles

\begin{tabular}{llll}
\hline Sample & $\begin{array}{l}\text { Water contact } \\
\text { angle }\end{array}$ & $\begin{array}{l}\text { Oil contact } \\
\text { angle }\end{array}$ & $\begin{array}{l}\text { Type of } \\
\text { emulsion }\end{array}$ \\
\hline Original $\mathrm{SiO}_{2}$ & 0 & 53 & No emulsion \\
$\mathrm{Si}-10 \mathrm{a}$ & No analysis & No analysis & $\mathrm{O} / \mathrm{W}$ \\
$\mathrm{Si}-10 \mathrm{~b}$ & 35 & 27 & $\mathrm{O} / \mathrm{W}$ \\
$\mathrm{Si}-15$ & 42 & 15 & $\mathrm{O} / \mathrm{W}$ \\
$\mathrm{Si}-30$ & 75 & 10 & $\mathrm{~W} / \mathrm{O}$ \\
\hline
\end{tabular}

$\mathrm{SiO}_{2}$ at $3,549 \mathrm{~cm}^{-1}$ (-OH stretching), $1,106 \mathrm{~cm}^{-1}$ ( $\mathrm{Si}-\mathrm{O}$ stretching) and $476 \mathrm{~cm}^{-1}$ (Si-O bending vibration), the modified $\mathrm{SiO}_{2}$ present characteristic bands of MPTMS at $2,985 \mathrm{~cm}^{-1}\left(\mathrm{C}-\mathrm{H}\right.$ stretching) and $1,710 \mathrm{~cm}^{-1}(\mathrm{C}=\mathrm{O}$
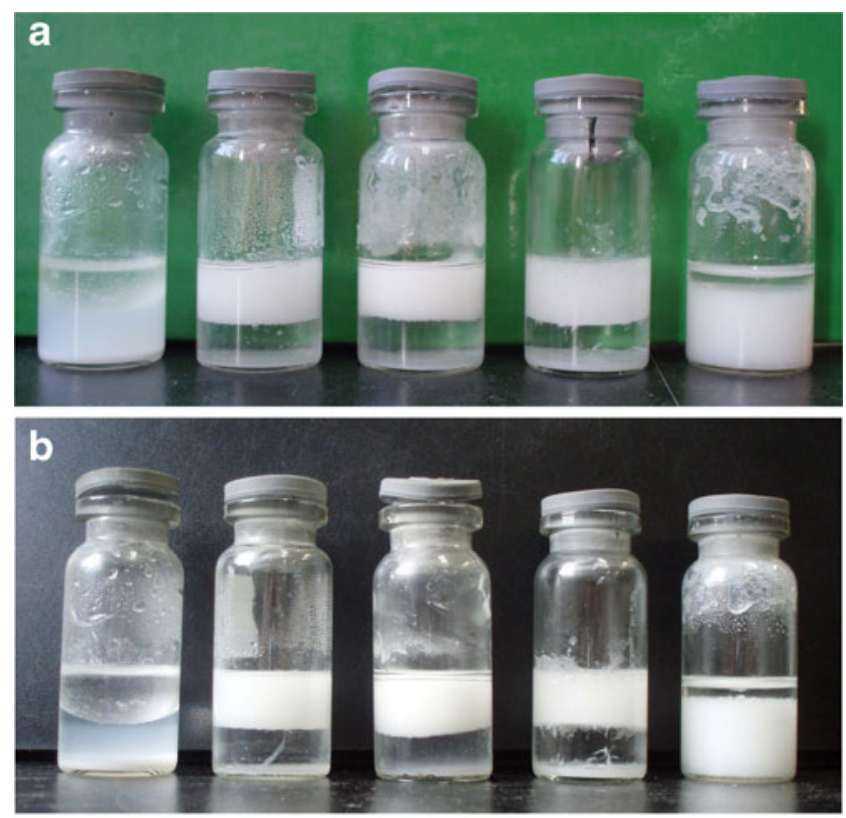

C

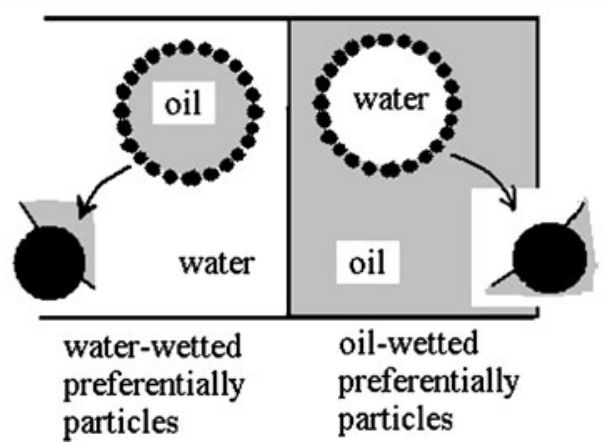

Fig. 4 Pickering emulsion stabilized by $\mathrm{SiO}_{2}$. a Digital photograph of emulsion $2 \mathrm{~h}$ after preparation. b Digital photograph of emulsion one month after preparation. c Formation mechanism of $\mathrm{O} / \mathrm{W}$ and $\mathrm{W} / \mathrm{O}$ emulsion. $\mathrm{SiO}_{2}$ used and emulsion type from left to right are original $\mathrm{SiO}_{2}$ (no emulsion), Si-10a (O/W), Si-10b (O/W), Si-15 (O/W) and $\mathrm{Si}-30(\mathrm{~W} / \mathrm{O})$, respectively. Oil volume fraction was 0.5 and $\mathrm{SiO}_{2}$ concentration in $\mathrm{SiO}_{2}$ suspension was $2.0 \mathrm{wt} \%$ 
stretching), which indicates that reactive MPTMS molecules have bonded to the surface of $\mathrm{SiO}_{2}$ particles. In Fig. 3, the weight loss observed between $50{ }^{\circ} \mathrm{C}$ and $150{ }^{\circ} \mathrm{C}$ is attributed to the elimination of adsorbed water. The weight loss of $3.8 \%$ (Fig. 3, $b$ ) and $7.7 \%$ (Fig. 3, c) from $300{ }^{\circ} \mathrm{C}$ to $350{ }^{\circ} \mathrm{C}$ is assigned to the decomposition of MPTMS. It can be inferred that the grafted ratio of added MPTMS was approximately $51.6 \%$ and $34.9 \%$ for Si-10b and Si-30, respectively.

\section{Formation of Pickering emulsion}

It is well established that the effective stabilization of Pickering emulsion is originated from a dense monolayer or multiplayer film formed by particles adsorbed irreversibly on the interface [17-20]. Many factors, such as character of particles, ratio of phases, $\mathrm{pH}$ value and particle concentration, have effect on stabilizing efficiency of particles. In case of spherical particle, the crucial parameter is its contact angle $\theta$ which indicates the wettability or hydrophilichydrophobic balance of the particle [7, 17, 21]. It has been empirically proved that the phase that preferentially wets the particles becomes the continuous phase of Pickering emulsion.

In this paper, contact angle of $\mathrm{SiO}_{2}$ particle was determined directly by a contact angle goniometer using water (denoted as $\theta_{\mathrm{aq}}$ ) and 1-dodecanol (denoted as $\theta_{\text {oil }}$ ) respectively. $2 \mathrm{uL}$ of water or 1-dodecanol (heated to $40{ }^{\circ} \mathrm{C}$ ) was putted on a $\mathrm{SiO}_{2}$ flake obtained by $30 \mathrm{Mpa}$ compressor. The results were shown in Table 1. As the

Fig. 5 Optical micrographs of droplets stabilized by a Si-10a, $\mathrm{O} / \mathrm{W}, \mathbf{b} \mathrm{Si}-10 \mathrm{~b}, \mathrm{O} / \mathrm{W}, \mathbf{c ~ S i}-15, \mathrm{O} /$ W, d Si-30, W/O, e Si-10b 1 month after preparation. The scale bars correspond to $50 \mu \mathrm{m}$

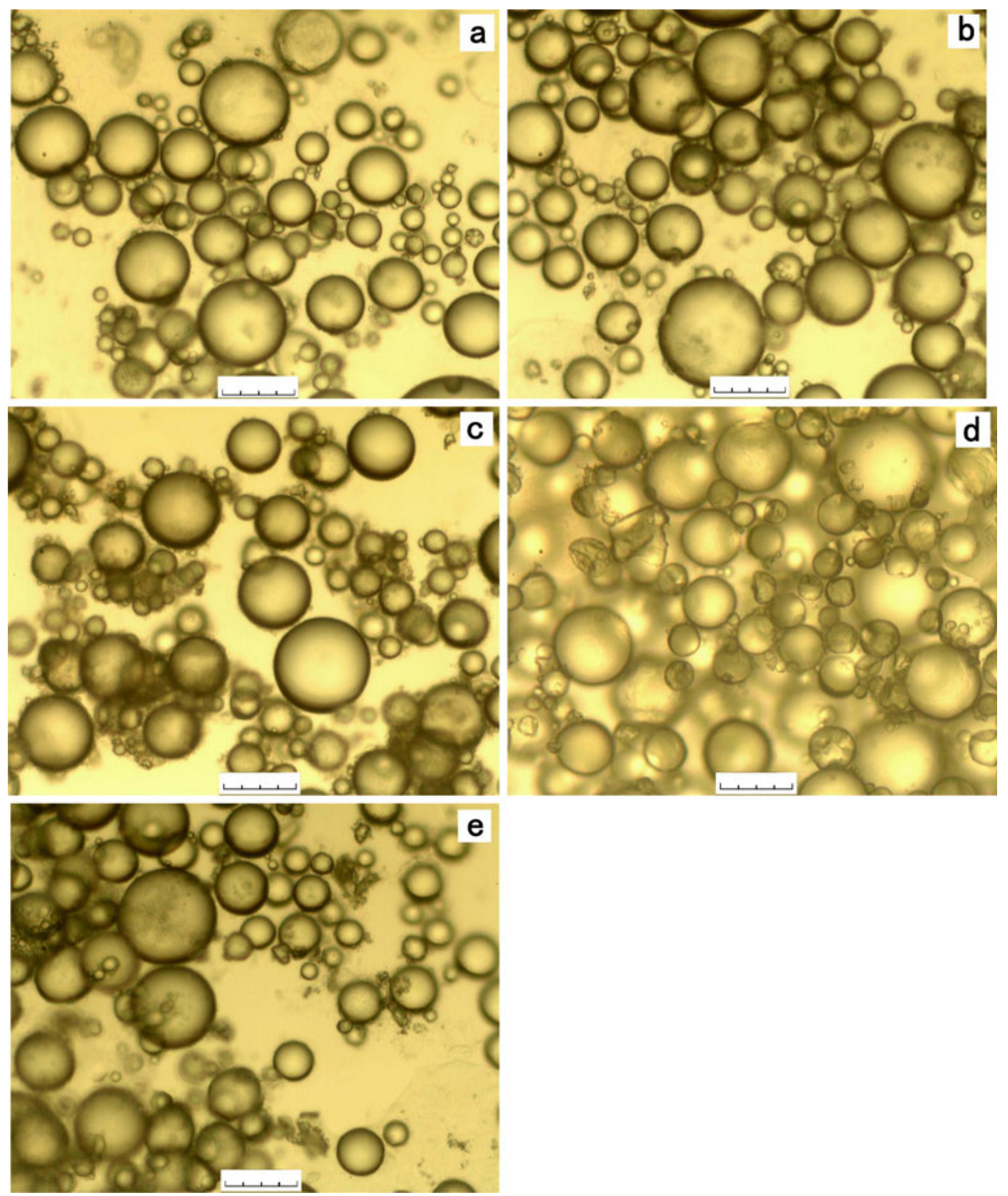


increase of MPTMS amount, $\theta_{\mathrm{aq}}$ increases while $\theta_{\text {oil }}$ decreases. The results confirmed that the wettability of nano- $\mathrm{SiO}_{2}$ particles was tunned significantly by modification of MPTMS. It is worthy noting that relative value of $\theta_{\text {aq }}$ and $\theta_{\text {oil }}$ is unqualified to evaluate the hydrophilic or hydrophobic character, because the method employed to detect $\theta$ is a relative method and the surface tension of water $(72.8 \mathrm{mN} / \mathrm{m})$ is much larger than that of 1 dodecanol $(26.9 \mathrm{mN} / \mathrm{m})$ [22].

Using different $\mathrm{SiO}_{2}$ particles, $\mathrm{O} / \mathrm{W}$ type and $\mathrm{W} / \mathrm{O}$ type emulsions were prepared as shown in Fig. 4a. No emulsion formed when original $\mathrm{SiO}_{2}$ employed as stabilizing particles due to its high hydrophilicity. W/O type emulsion formed when $\mathrm{Si}-30$ was used because $\mathrm{Si}-30$ particles are wetted preferentially by styrene while $\mathrm{O} / \mathrm{W}$ type emulsions obtained when Si-10a, Si-10b and Si-15 was used individually. The formation mechanism of Pickering emulsion was illustrated in Fig. 4c. When water-wetted preferentially particles were used, a larger region of particle immerses in water and the curve line deflects alongside styrene droplets. As a result, $\mathrm{O} / \mathrm{W}$ emulsion forms. When oilwetted preferentially particles were used, the curve line deflects alongside water droplets and W/O emulsion forms. The emulsion cream quickly after preparation because the droplets are so big as to $20 \sim 50 \mu \mathrm{m}$ (see Fig. 5 below) and density of styrene is much lower than that of water.
The morphology of droplets was examined by optical microscopy with a high performance digital camera. The diameter of droplets was demarcated by a scale-mark software. The droplets of both $\mathrm{O} / \mathrm{W}$ and $\mathrm{W} / \mathrm{O}$ emulsions are spherical with similar size distribution from 20 to $50 \mu \mathrm{m}$ (Fig. 5). However, the droplets present different clustering character. Droplets stabilized by Si-10a is well dispersed (Fig. 5a), while most of the droplets stabilized by Si-15 (Fig. 5c) cluster together in a disordered fashion. All emulsions are very stable to coalescence and Ostward ripening. Even one month after preparation, the appearance and droplet size have no appreciable change as shown in contrast by Fig. $4 \mathrm{a}$ to Fig. $4 \mathrm{~b}$ and Fig. $5 \mathrm{~b}$ to Fig. 5e), respectively.

\section{Morphology of polystyrene/ $\mathrm{SiO}_{2}$ composites}

In this study, $\mathrm{O} / \mathrm{W}$ emulsion was employed to prepare $\mathrm{PS} /$ $\mathrm{SiO}_{2}$ composites by radical polymerization initiated by oilsoluble AIBN. The suspension obtained after polymerization was diluted and dropped onto a glass slide, followed by volatilizing to dry and being characterized by optical microscope. The optical micrograph of composites using $2.0 \mathrm{wt} \%$ of Si-10b as stabilizer was shown in Fig. 6a. The composites are spherical with the diameter of $20 \sim 50 \mu \mathrm{m}$, which is consistent with the droplet template. SEM micrograph in Fig. $6 \mathrm{~b}$ and $\mathrm{c}$ indicates that the composites
Fig. $6 \mathrm{PS} / \mathrm{SiO}_{2}$ composites obtained by $\mathrm{O} / \mathrm{W}$ Pickering emulsion polymerization. a Optical micrograph with scale bar of $100 \mu \mathrm{m}$. b SEM micrograph with scale bar of $10 \mu \mathrm{m}$. c SEM micrograph with scale bar of $10 \mu \mathrm{m}$
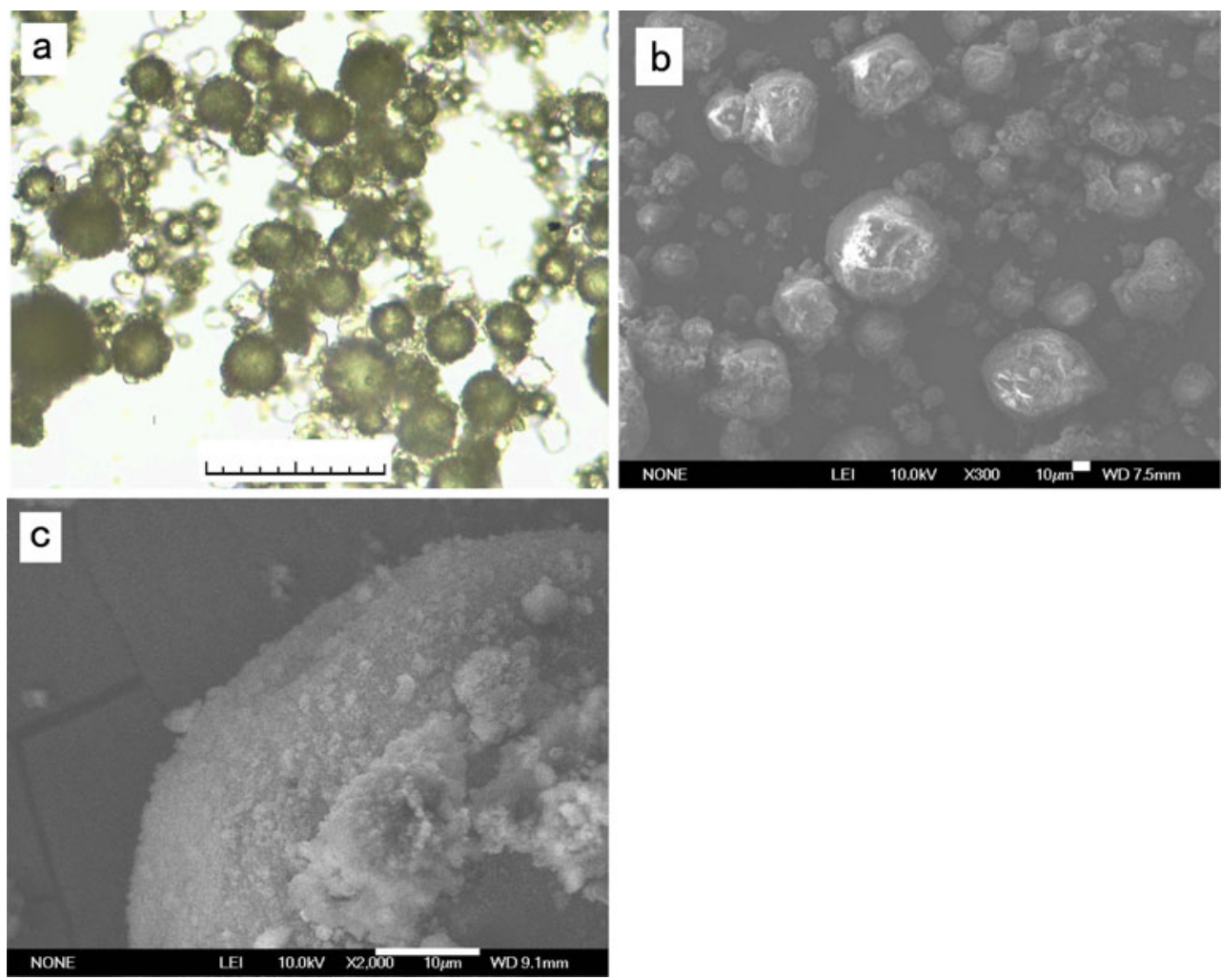
have rugged surface. This morphology may be attributed to two mechanisms. Firstly, $\mathrm{SiO}_{2}$ aggregations form during polymerization and locate on the surface. Secondly, PS particles formed by secondary nuclei assemble on the surface of composites. Although most of hydrophobic AIBN decomposes and initiates polymerization inside the droplets, a small amount of decomposed initiator diffuses into the aqueous phase because of its slight solubility in water, and initiates the monomer dissolved in aqueous phase [23]. After the oligomer reaches a critical length, it no longer dissolves in water, but precipitates to form secondary nuclei. $\mathrm{SiO}_{2}$ particles are too large in quantity to move as free as low molecular surfactant employed in traditional emulsion, so the secondary nuclei cannot enter the droplet as freely as those in traditional emulsion polymerization. The secondary nuclei absorb monomer and polymerize on the droplet surface, resulting in the formation of micron-sized PS particle on the surface of prepared composites.

\section{FTIR spectra of prepared composites}

In order to verify that chemical bonds exist between PS core and $\mathrm{SiO}_{2}$ shell, FTIR spectra were employed. The
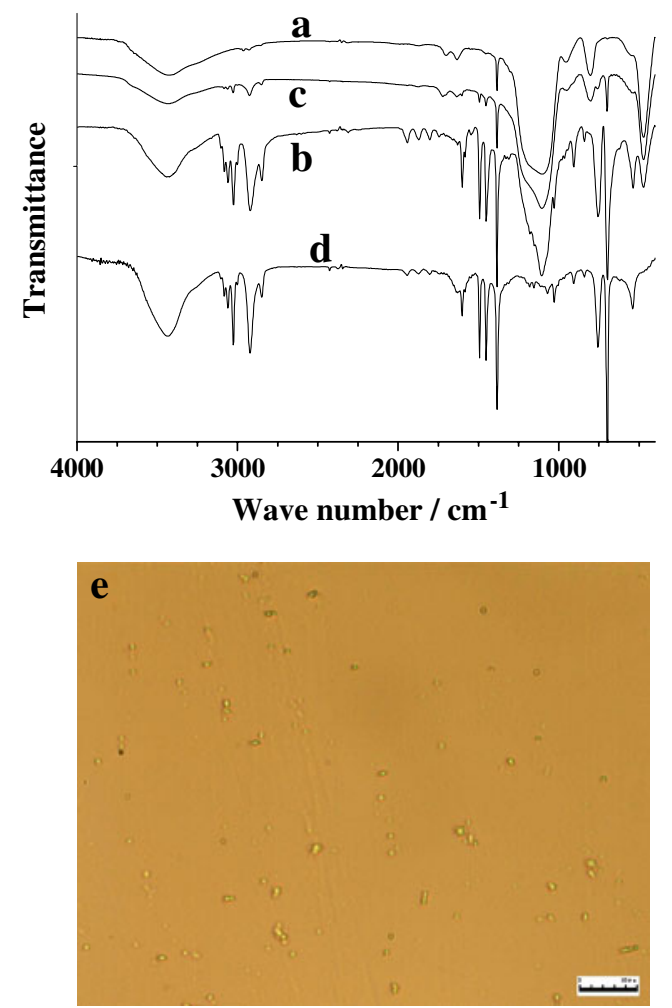

Fig. 7 FTIR spectra of (a) Si-10b, (b) $\mathrm{PS} / \mathrm{SiO}_{2}$ composites, (c) precipitated $\mathrm{SiO}_{2}$ separated from composites, (d) PS separated from composites and optical micrograph of $\mathrm{SiO}_{2}$ separated from composites with scale bar of $10 \mu \mathrm{m}(e)$ composites were dissolved in toluene, followed by centrifugation to separate $\mathrm{SiO}_{2}$ precipitation and PS solution. The PS solution was diluted into ethanol to precipitate PS and the precipitation $\mathrm{SiO}_{2}$ was redispensed in toluene and separated by centrifugation twice to remove residual PS. FTIR spectra of $\mathrm{Si}-10 \mathrm{~b}, \mathrm{PS} / \mathrm{SiO}_{2}$ composites, $\mathrm{PS}$ and $\mathrm{SiO}_{2}$ separated from composites were shown in Fig. 7. No particle larger than $1 \mu \mathrm{m}$ presents in the optical micrograph of precipitated $\mathrm{SiO}_{2}$ (shown in Fig. 7,e), from which we can infer that all composites were destroyed by toluene and PS ungrafted on $\mathrm{SiO}_{2}$ was removed entirely from the precipitation $\mathrm{SiO}_{2}$. Both the characteristic bands of $\mathrm{SiO}_{2}$ $\left(3,549,1,106\right.$ and $\left.476 \mathrm{~cm}^{-1}\right)$ and polystyrene $(1,650 \sim$ $1,400,760$ and $693 \mathrm{~cm}^{-1}$ ) present in spectrum of composite (Fig. $7, b$ ), verifying that $\mathrm{PS} / \mathrm{SiO}_{2}$ composites were successfully synthesized. Furthermore, the characteristic bands of PS also present in the spectrum of precipitated $\mathrm{SiO}_{2}$ (Fig. 7, c), from which it can be inferred that the $\mathrm{C}=$ $\mathrm{C}$ bands on $\mathrm{SiO}_{2}$ particle surface have polymerized with styrene, thus PS core and $\mathrm{SiO}_{2}$ shell were covalently bonded in the prepared composites.

\section{Effect of $\mathrm{SiO}_{2}$ concentration on polymerization}

It has been verified that particle concentration has an important effect on the properties of Pickering emulsion. In this work, the effect of $\mathrm{SiO}_{2}$ concentration on polymerization and morphologies of $\mathrm{PS} / \mathrm{SiO}_{2}$ composites were studied. After polymerization, the appearance of emulsion changed from cream to suspension of individual composites in case of $\mathrm{SiO}_{2}$ concentration as $4 \%$ and $2 \%$ or conglutinating blocks in case of $\mathrm{SiO}_{2}$ concentration as $1 \%$ and $0.5 \%$. Figure 8 shows the morphologies of composites prepared with different concentration of Si-10b. The difference of result originates from the difference of particle coverage, defined as the percent of droplet surface covered by particles. Large amount of stabilizing particles results in a denser layer to protect droplets against coalescence and high stability during polymerization. Consequently, individual composites form when $\mathrm{SiO}_{2}$ concentration is larger than $2.0 \%$. When $\mathrm{SiO}_{2}$ concentration is $1.0 \%$, the stability of emulsion decline during polymerization and some $\mathrm{SiO}_{2}$ particles detach away from the droplet surface to the continuous phase, which results in the formation of $\mathrm{SiO}_{2}$ aggregation as shown in Fig. 8c. When $\mathrm{SiO}_{2}$ concentration is $0.5 \%$, the emulsion changed to conglutinating blocks containing aggregated $\mathrm{SiO}_{2}$ and composites.

The average diameter of emulsion droplets increases as the particle concentration decreases [24, 25]. In this study, size distribution of prepared composites at different $\mathrm{SiO}_{2}$ concentration was illustrated in Fig. 9. The average diameter of composites obtained at $\mathrm{SiO}_{2}$ concentration of 
Fig. 8 Optical micrographs of $\mathrm{PS} / \mathrm{SiO}_{2}$ composites obtained from emulsion stabilized by different concentration of $\mathrm{Si}-10 \mathrm{~b}$. a $2.0 \%$, b $4.0 \%$, c $1.0 \%$, d $0.5 \%$.

The scale bars correspond to $100 \mu \mathrm{m}$

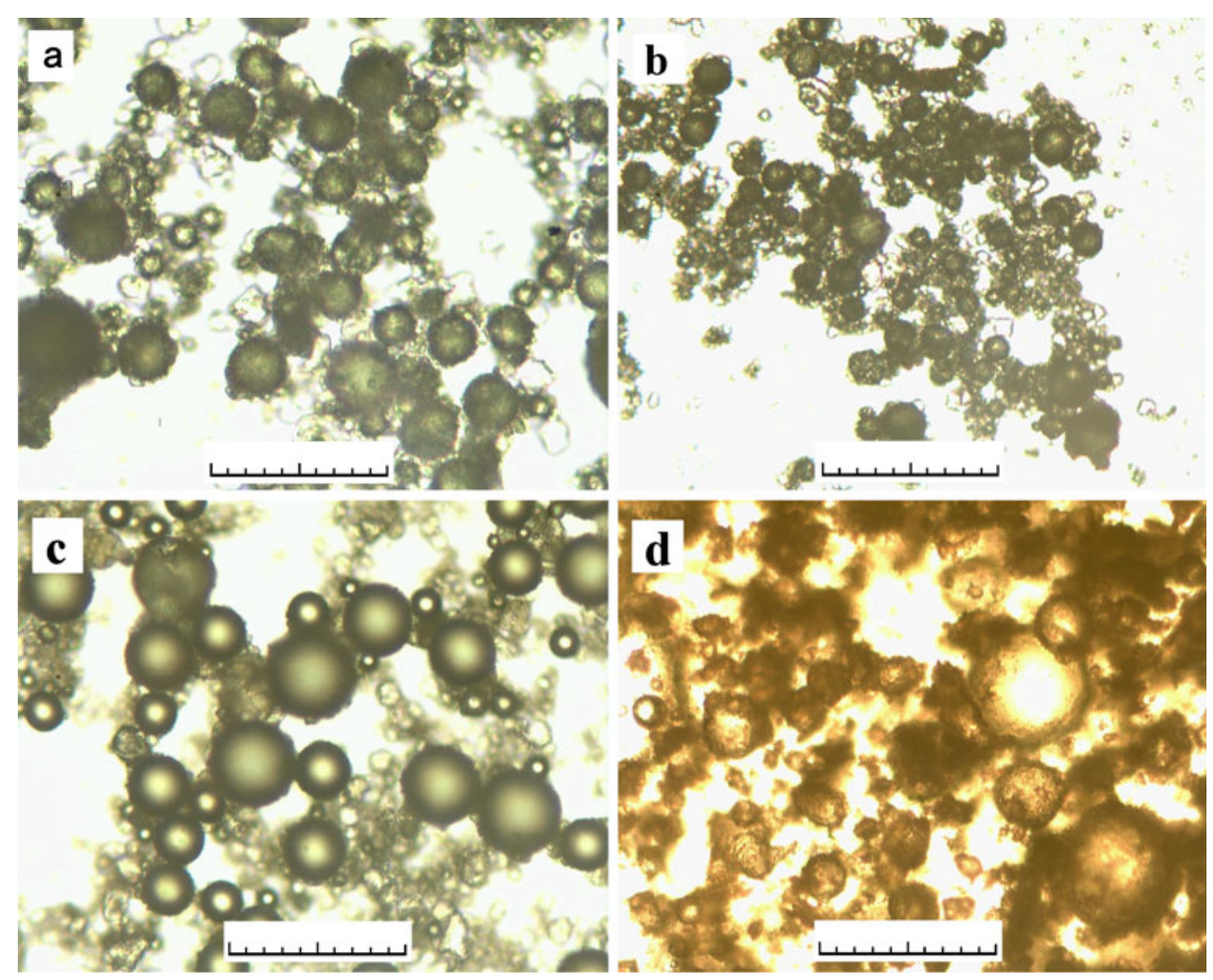

$4 \%, 2 \%$ and $1.0 \%$ was $13.6 \mu \mathrm{m}, 26.4 \mu \mathrm{m}$ and $48.1 \mu \mathrm{m}$, respectively. Especially, size distribution of composites obtained at $\mathrm{SiO}_{2}$ concentration of $1.0 \%$ is shown exponentially in the inset graph in Fig. 9. Three kinds of different particle with average diameter of $70 \mathrm{~nm}, 420 \mathrm{~nm}$ and $48.1 \mu \mathrm{m}$ may be corresponded to original $\mathrm{Si}-10 \mathrm{~b}$ particles, aggregations of Si-10b particles and composites respectively. This is consistent with the optical micrographs as shown in Fig. 8c.

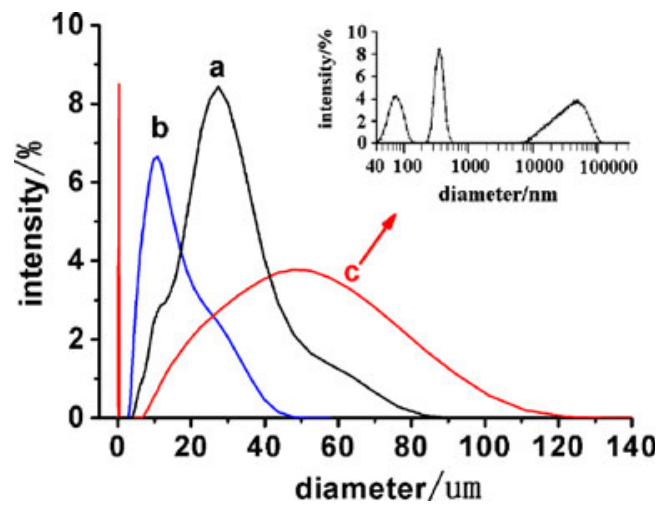

Fig. 9 Size distribution of $\mathrm{PS} / \mathrm{SiO}_{2}$ composites obtained from emulsion stabilized by different concentration of Si-10b. (a) $2.0 \%$ (average diameter $26.4 \mu \mathrm{m}$ ), (b) $4.0 \%$ (average diameter $13.6 \mu \mathrm{m}$ ), (c) $1.0 \%$ (average diameter $48.1 \mu \mathrm{m}$, three peaks were illustrated as inset graph)

\section{Conclusions}

We have modified $\mathrm{SiO}_{2}$ with MPTMS to change its surface wettability. By modification, the wettability of particles can be tuned significantly, hence, the modified $\mathrm{SiO}_{2}$ particles can assemble spontaneously on the oil/water interface and can be used to stabilize Pickering emulsion.

By Pickering emulsion polymerization, covalentlybonded $\mathrm{PS} / \mathrm{SiO}_{2}$ composites were successfully synthesized in a surfactant-free emulsion system. Low molecular surfactant was replaced completely by organically modified $\mathrm{SiO}_{2}$ particles. $\mathrm{SiO}_{2}$ concentration has an important effect on the polymerization and morphology of composites. Individual composites formed when $\mathrm{SiO}_{2}$ concentration in suspension is above $2.0 \mathrm{wt} \%$, while conglutinated block obtained when $\mathrm{SiO}_{2}$ concentration in suspension is below $1.0 \mathrm{wt} \%$. By grafting reactive $\mathrm{C}=\mathrm{C}$ group on the particles, covalent bonds formed between stabilizing particles and polymer core. The research puts forward a simple and robust way to fabricate other inorganic-organic hybrid composites based on covalent bonds.

Open Access This article is distributed under the terms of the Creative Commons Attribution Noncommercial License which permits any noncommercial use, distribution, and reproduction in any medium, provided the original author(s) and source are credited. 


\section{References}

1. Aveyard R, Binks BP, Clint JH (2003) Emulsions stabilised solely by colloidal particles. Adv Colloid Interface Sci 100:503-546

2. Binks BP (2003) Particles as surfactants-similarities and differences. Curr Opin Colloid Interface Sci 7:21-41

3. Catherine PW, Alex MD, James KB, Gregory GW (2006) Nanoparticle adsorption and stabilisation of surfactant-free emulsions. J Colloid Interface Sci 301:342-345

4. Binks BP, Desforges A, Duff DG (2007) Synergetic stabilization of emulsions by a mixture of surface-active nanoparticles and surfactant. Langmuir 23:1098-1106

5. Cui ZG, Shi KZ, Cui YZ, Binks BP (2008) Double phase inversion of emulsions stabilized by a mixture of $\mathrm{CaCO}_{3}$ nanoparticles and sodium dodecyl sulphate. Colloids Surf, A Physicochem Eng Asp 329:67-74

6. Francesca R, Michele F, Libero L, Giuseppe L, Eva S, Alessandra Z (2008) Liquid-liquid interfacial properties of mixed nanoparticle-surfactant systems. Colloids and Surfaces A: Physicochem Eng Aspects 323:99-108

7. Eric D (2009) Hydrocolloids as emulsifiers and emulsion stabilizers. Food Hydrocolloids 23:1473-1482

8. Kirsty EA, Brent SM, Eric D (2008) Development of a model whipped cream: effects of emulsion droplet liquid/solid character and added hydrocolloid. Food Hydrocolloids 22:690-699

9. Justyna F, Marie-Alexandrine B, Jean-Pierre V (2009) Pickering w/o emulsions: drug release and topical delivery. Int J Pharm 368:7-15

10. Leonard MC (2008) Dynamics of controlled release systems based on water-in-water emulsions: a general theory. J Control Release 131:5-13

11. He Y (2005) Synthesis of polyaniline/nano- $\mathrm{CeO}_{2}$ composite microspheres via a solid-stabilized emulsion route. Mater Chem Phys 92:134-137

12. He YJ, Yu XY (2007) Preparation of silica nanoparticle-armored polyaniline microspheres in a Pickering emulsion. Mater Lett 61:2071-2074

13. He YJ (2005) Preparation of polyaniline microspheres with nanostructured surfaces by a solids-stabilized emulsion. Mater Lett 59:2133-2136
14. Chen JH, Cheng CY, Chiu WY, Lee CF, Liang NY (2008) Synthesis of $\mathrm{ZnO} /$ polystyrene composites particles by Pickering emulsion polymerization. Eur Polym J 44:3271-3279

15. Wen NG, Tang QQ, Chen M, Wu LM (2008) Synthesis of PVAc/ $\mathrm{SiO}_{2}$ latices stabilized by silica nanoparticle. J Colloid Interface Sci 320:152-158

16. Binks BP, Lumsdon SO (2000) Catastrophic phase inversion of water-in-oil emulsions stabilized by hydrophobic silica. Langmuir $16: 2539-2547$

17. Timothy NH, Robert JP, George VF, Graeme JJ (2008) The role of particles in stabilising foams and emulsions. Adv Colloid Interface Sci 137:57-81

18. Catherine PW, Alex MD, James KB, Gregory GW (2006) Nanoparticle adsorption and stabilisation of surfactant-free emulsions. J Colloid Interface Sci 301:342-345

19. Ming FH, Michael GN, Anthony DD, Andreas RB, Vernita DG, Chen X, John WH, David AW (2005) Self-assembled shells composed of colloidal particles: fabrication and characterization. Langmuir 21:2963-2970

20. Binks BP, Rocher A (2009) Effects of temperature on water-in-oil emulsions stabilised solely by wax microparticles. J Colloid Interface Sci 335:94-104

21. Stiller S, Gers-Barlag H, Lergenmueller M, Pflücker F, Schulz J, Wittern KP, Daniels R (2004) Investigation of the stability in emulsions stabilized with different surface modified titanium dioxides. Colloids Surf, A Physicochem Eng Asp 232:261-267

22. Cheng NL (2007) Handbook of commonly-used solvents (in Chinese). Chinese Press of Chemical Industry, Beijing

23. Ma GH, Li JH (2004) Compromise between dominant polymerization mechanisms in preparation of polymer microspheres. Chem Eng Sci 59:1711-1721

24. Yang F, Liu SY, Xu J, Lan Q, Wei F, Sun DJ (2006) Pickering emulsions stabilized solely by layered double hydroxides particles: the effect of salt on emulsion formation and stability. J Colloid Interface Sci 302:159-169

25. Perro A, Meunier F, Schmitt V, Ravaine S (2009) Production of large quantities of "Janus" nanoparticles using wax-in-water emulsions. Colloids Surf, A Physicochem Eng Asp 332:57-62 